Article

\title{
Remote Working for Sustainability of Organization during the COVID-19 Pandemic: The Mediator-Moderator Role of Social Support
}

\author{
Marko Slavković $^{1, *} \mathbb{( \mathbb { D }}$, Stefan Sretenović $^{2}$ and Marijana Bugarčić ${ }^{1}$ \\ 1 Department of Management and Business Administration, Faculty of Economics, University of Kragujevac, \\ 34000 Kragujevac, Serbia; msimic@kg.ac.rs \\ 2 Independent Researcher, 34000 Kragujevac, Serbia; st.sretenovic@gmail.com \\ * Correspondence: mslavkovic@kg.ac.rs
}

check for updates

Citation: Slavković, M.; Sretenović, S.; Bugarčić, M. Remote Working for Sustainability of Organization during the COVID-19 Pandemic: The

Mediator-Moderator Role of Social Support. Sustainability 2022, 14, 70. https://doi.org/10.3390/su14010070 Academic Editor: Ioannis Nikolaou

Received: 9 November 2021

Accepted: 28 November 2021

Published: 22 December 2021

Publisher's Note: MDPI stays neutral with regard to jurisdictional claims in published maps and institutional affiliations.

Copyright: (c) 2021 by the authors. Licensee MDPI, Basel, Switzerland. This article is an open access article distributed under the terms and conditions of the Creative Commons Attribution (CC BY) license (https:// creativecommons.org/licenses/by/ $4.0 /)$.

\begin{abstract}
Remote working became a widespread business practice during the COVID-19 pandemic as an organizational response to protect employees' health and maintain business continuity. The aim of this paper is to reveal the role of social support in the relationship among NWHI, NHWI and loneliness, and work engagement and job performance. The study respondents were employees with a remote working status in Serbian companies, and a total of 226 valid surveys were collected. The PLS-SEM approach was deployed to test the hypothesized relationship between named variables. A standard bootstrapping procedure was used to reveal direct and indirect effects among latent variables. Results indicate a strong and positive direct association between social support and work engagement and job performance, while mediation and moderation of the role of social support were mostly confirmed but with some results opposite to what was expected. Social support was not able to buffer a negative home-work interaction and loneliness within remote working. The study offers insight into the role of social support and recommendations for managing the antecedents and consequences of remote working, with the aim to determine a sustainable model for extensive application, not only during the COVID-19 pandemic, but in regular times.
\end{abstract}

Keywords: remote working; social support; work engagement; job performance; work-home interaction; COVID-19 pandemic

\section{Introduction}

On 15 March 2020, a state of emergency was declared in the Republic of Serbia, caused by the crisis subsequently called the COVID-19 pandemic [1], and strict measures aiming to mitigate the spread of the virus and disease were introduced, such as restriction of people's movements and closure of bars and restaurants, shopping malls, sport activities, etc. [2]. In such circumstances, various actions were taken by organizations in order to reduce the risks caused by COVID-19. In line with urgent responses, most organizations were forced to create new business strategies, introduce innovative marketing activities and adopt alternative business models [3]. As well as being a health and social emergency, the current pandemic also poses a significant threat for organizations, especially to their business continuity. With the outbreak of the COVID-19 pandemic, organizations have been forced to provide adequate responses on such unpredictable events [4]. In order to continue their business activities, provide business continuity and protect their employees, many companies have executed a fast transition process for their employees from regular work in the office to remote working [5].

According to Baruch and Nicholson, four factors are crucial for successful implementation of remote working: individual, organizational, job factors and the home/work interface. The main individual factors are composed of the ability to work alone, selfmotivation and factors related to organization skills. The organizational factors that should support remote working are related to communication among employees, organizational 
culture, leadership and an appropriate system; such factors are defined as the main variable for successful implementation of remote working. Jobs with low and very high levels of autonomy are the most suitable for implementation of remote working. Jobs with a low level of autonomy can be easily controlled remotely, while those with a high level of autonomy mostly involve autonomous activities. Work-life balance and family status refer to the last important factors and are impacted by number of children, family members, etc. [6]. Additionally, according to Kowalski and Swanson, the most important factors for successful implementation are procedures, formal and informal communication and the support of managers and supervisors. Regarding employees, it is very important to obtain proper family support and work-life balance [7].

The pandemic caused by COVID-19 can not only be defined as a health crisis, but also an economic crisis. Many businesses and industries were closed and forced to manage specific challenges, both for employees and employers [8]. In such circumstances, the pandemic has accelerated the trend of effective remote working implementation in many companies, in order to protect their business and employees [9]. There is no supporting research in the academic literature where remote working implementation is not optional but necessary for organizations responding to a crisis [10]. When COVID-19 appeared, remote working was a completely new experience for most organizations. Without previous preparation and an adaptation period, organizations were faced with significant changes in terms of rules and procedures, business models, operational activities, job design, organizational cultures, leadership and HR practices. Additionally, remote workers were forced to manage the following variables: work/life balance, job stress, communication and knowledge sharing issues. The management approach where employee's evaluation is performed on the "time presence in the office" is completely useless for the concept of remote working.

Appropriate implementation of the remote working concept has several positive effects. The research conducted by Bloom et al. [11] within employees in a call center revealed increasing productivity, a lower level of intention to leave the organization by employees and a higher job satisfaction rate compared with non-remote working employees. According to the analysis of the Chartered Institute of Personnel Development (CIPD), the absence rate within employees was lower than $56 \%$ among employees, after remote working implementation [12]. However, implementation of such a concept requires serious caution because such positive effects are usually followed by several side effects. Work efficiency is declared by many organizations as one the severest concerns during remote working [5]. Building trust between managers and employees is a necessary condition for successful implementation of remote working. Managers have an important role in successful implementation by providing reliable responsibility, competence and professionalism [13]. In order to adequately manage remote workers, effective leadership is very important. Leaders have to develop respect, trust, an adequate communication level with employees, company culture and common values. Adequate communication is a necessary condition for the management of remote workers. Not only do meetings with the team have to be regularly performed, but also one to one with employees. Additionally, social connections among employees are vital in order to share the same values and trust. This can be supported by creating informal meetings [9].

Some of the most common side effects are working hours, knowledge sharing issues within employees, loneliness, increasing levels of stress, isolation and work-life balance issues [14]. From employees' point of view, remote working might concern their careers, advancements, training, and flexibility [15]. Remote working can also be evaluated through its positive effects on sustainability and the environment. Elimination of time wasted commuting and a decrease in physical presence in the office, traveling and using transportation directly reduce pollution, $\mathrm{CO}_{2}$ emissions, noise and usage of fuel and energy [16].

Cyber security is a particular challenge for many organizations working remotely. Although many organizations implement various security measures, such as double passwords for computer access and a virtual private network (VPN), remote workers usually 
forget security procedures regarding e-mails, suspicious web sites and opening of improper attachments [17]. Organizations should provide employees with adequate infrastructure, such as protective software and ICT procedures, while employees should understand such procedures and acquire the appropriate level of knowledge [18]. Additionally, the costs of remote working should be recognized and reimbursed to employees. These costs break down as follows: desktop or laptop, mobile phones, internet, software and hardware. The companies should establish a company policy that clearly shows what costs can be reimbursed to employees and what the approval flow is like [19].

There are differing conclusions about the impact of remote working on work-life balance. Some studies show increasing job stress due to the overlap of business and private life when performing work activities from home [20], while other studies have shown that increasing autonomy reduces work stress and correlates positively with the work-life balance of remote workers [21]. According to a study by Anderson and Kelliher [22], 59\% of interviewees declared that working remotely had a positive effect on job stress, $32 \%$ said that working remotely had no impact, while $9 \%$ revealed that working remotely had a negative impact on the degree of job stress. Additionally, some other studies revealed that a higher level of autonomy caused by remote working has a positive impact on reducing job stress, thought here are also conclusions that suggest that remote working negatively affects work-life balance and consequently increases job stress [23,24]. Managers have to pay special attention to the side effects of remote working. Changes in leadership approach, organizational culture, human resources and result evaluation are required to minimize or offset negative effects and strengthen positive ones. Only with the right changes and management support are remote workers able to take advantage of all the positive effects and benefits of such a working concept. Otherwise, there is a high risk that these positive effects will be outweighed by the negative.

Various studies have come to conflicting conclusions not only about the impact of remote working on work-life balance and job stress, but also about the impact on productivity. Research performed by Bloom et al. concluded that remote working has a positive on productivity [11], while Battiston et al. [25] revealed that productivity in the public sector in the United Kingdom is higher for regular office work than for remote work, especially for complex tasks. Additionally, the research conducted in Japanese companies revealed that remote working has a negative impact on productivity [26,27]. It should be noted, however, that these studies were conducted under different circumstances, as there was no pandemic in 2015 or 2017.

\section{Literature Review and Hypotheses Development}

\subsection{Job Performance}

In general, remote workers' job performance depends on individual personality [28-30] and organizational context, including variables such as culture, technical support, manager's trust, human resource support, financial support for working-from-home and training for working-from-home [31]. Our study focused on the remote working challenges that come from an organizational context, but the term "organizational context" required further clarification as remote working was forcibly converted to working-from-home during the COVID-19 outbreak. The occasions in which remote working has become the standard form of work for most employees have been related to the difficult business conditions caused by the COVID-19 pandemic and the measures taken by the authorities, which are known as "lockdown". To ensure the health of employees on the one hand and to maintain business continuity on the other hand, companies needed fast response and flexible managerial actions in the form of displaced jobs. Most of employees began to remotely work in their own job from home without preparation. Typically, initial technical training was conducted for employees who encountered a remote working mode for the first time, to allow them to perform their tasks effectively. Research conducted by Hitt and Tambe [32] supported the perspective that the implementation of the remote working system was able to improve productivity and efficiency, especially in cases involving previously IT-complementary 
work organizations. The organizations with experience of remote work had an advantage and a better predisposition for normal job performance in their remote workers during the COVID-19 pandemic, though most organizations were not in that position [32].

Work from organizations' offices was moved to their employees' homes overnight, creating a specific work arrangement for individuals. Wang et al. [33] described remote working as a flexible work arrangement whereby workers work in remote locations, staying without personal contact with coworkers there, but with the opportunity to communicate with them via technology. What the authorities called "social distance" referred to physical distancing; people stayed connected through technology. The employees were faced with the challenges of anew working environment and asked to perform excellently in their role as remote workers. The reduction in business activities led to decreasing company budgets, which meant that compensation packages for remotely worked employees were not stimulative, with a negative potential for job performance. Moreover, additional psychological pressure and stress appeared with the increased threat of job loss due to downsizing strategies conducted by companies, which were caused by the economic crisis. Social isolation and stress were negatively related to perceived productivity during remote working [34].

Murphy and Kroeker [35] describes performance as a "set of behaviors that are relevant to the goals of the organization or the organizational unit in which a person works". This is also affected by formal and non-formal training activities, experience and motivation, and can be moderated by variables such as task responsibility, work environment and social context. Performance during remote working was especially impacted by low formal training activities due to organizations' unpreparedness and lack of experience for specific work arrangements. Some obstacles to job performance were perceived and organizational support was established to prevent a lack of performance in remote working. Randall et al. [36] also reported that organizational support was positively related to job performance.

Remote working during the COVID-19 pandemic had specific status in the terms of formality. Before the COVID-19 outbreak, remote working was characterized as a formal but flexible working arrangement. With the "wave" of remote working caused by the COVID-19 pandemic, it became tacitly formal as the result of a compromise between the organization and the employee, namely, to remain employed, but with no changes to the formal contract. It created a specific informal relationship that could affect performance. De Menezes and Kelliher [37] state that informal flexible working arrangements, including remote working, had no direct association with performance, but positive direct associations between informal flexible working and organizational commitment and between organizational commitment and performance were registered. The same research has also shown that formal flexible working arrangements, including remote working, is positively related to organizational commitment, but negatively associated with performance. The degree of formality reported caused statistically significant differences in performance, suggesting that a higher degree of formality in remote working leads to less work performed. Instead of an option, remote working became the standard work arrangement, with potentially significant implications for the performance of remote workers.

\subsection{Work Engagement}

The concept of work engagement was first observed by consultants and managers, before it attracted the attention of academics, inducing numerous researchers who developed the theory and distinguished it from related concepts. The terms "work engagement" and "employee engagement" are used interchangeably in the literature, however some authors [38] have clarified the difference, describing work engagement as more specific because as it relates to employee's work, while employee engagement is a broader concept that relates not just to work but to the organization as a whole. The first conceptualization of work engagement came from Kahn [39] who interpreted it as the "harnessing of organization members' selves to their work roles: in engagement, people employ and express 
themselves physically, cognitively, emotionally and mentally during role performances". Maslach et al. [40] described engagement as the antithesis or positive antipode of burnout. Schaufeli et al. [41] defined work engagement as a positive, fulfilling, work-related state of mind that is characterized by vigor, dedication and absorption. Vigor is explained as a high level of energy and mental resilience during work tasks, dedication indicates strong involvement in one's work and absorption relates to full concentration on performing work [42]. Some researchers have suggested that work engagement is very close to, but not the same as, job involvement, and actually indicates how employees devote themselves to work [43]. Schaufeli [44] noted that the engaged employees invested a lot of effort in performing their jobs because of identification with it, and suggested that work engagement substantially differs from related concepts such as job satisfaction and workaholism. It indicated that work engagement is a unique and multi-faceted concept with high potential for management practices and in academic research. Engaged employees demonstrate that they are actively included in work roles and perform those roles with a high level of cognitive and emotional relatedness [44].

Numerous factors have been found to be determinants of work engagement in the literature. Generally, these can be classified as predictors derived from organizational context and factors related to the characteristics of employees as individuals, with more attention paid to organizational factors. Richman argued that management practices and work environment are able to achieve a greater influence on engagement than the age, gender or personality of employees [45]. Job characteristics and organizational support were significant predictors of job engagement [46]. Research on the work engagement of nurses has shown that it can be increased if satisfaction with professional status and interaction in work increases [47]. Perceived organizational support and the congruence of values were positively and statistically significantly related to job engagement [48]. Bakker stated that work engagement is predicted by job resource and personal resource, with high relevance to job performance [49]. Brunetto et al. [50] found that job satisfaction and well-being positively affect employee engagement. Summarizing previous research, Al Mehrzi and Singh [51] proposed the model of employee engagement as a dependent variable influenced by four independent variables, such as organizational culture, leadership, perceived organizational support and teamwork. The engagement climate and job resource, represented by job autonomy, job variety and supervisor support, were positively related to engagement at work [52]. Work design, as a predictor which belongs to organizational factors, appears to be an important determining factor for engagement. This is also supported by research suggesting that motivating job characteristics allow managers to be better engaged at work, leading to the reduced likelihood of their leaving the organization [53]. Recent research has shown that job demands were negatively related to the work engagement of intensive care professionals [54], taking into account the factors with a negative impact on engagement.

Consultants, human resource management practitioners and academic researchers found many arguments as to why managers need to support work engagement. Work engagement is a positive prediction of job satisfaction and a negative prediction of intention to leave an organization [46]. It was also supported by Zhong, Wayne and Liden [55], who found that work engagement is negatively related to intention to quit an organization. By enhancing work engagement, organizations are able to reduce employee turnover and improve the workforce stability index. Bakker and Demerouti [42] have suggested that engaged employees perform better because they experience positive emotions and better health, and transfer their engagement to others by promoting a better work climate for their coworkers. Job engagement and task performance were positively and statistically significantly related [48], and engagement positively influenced affective commitment [50]. Summarizing the results of an earlier research study, Knight, Patterson and Dawson [56] argued that work engagement can be affective, and contemporary organizations need engaged employees in order to attain a sustainable competitive advantage.

In our research, we used the term "work engagement" to underline the specific work context during remote work, especially since each remote worker has less physical 
interaction with their organization. Insisting on this term is not decisive because most recent research only used "engagement". The greatest importance for our research lay in the context of remote working during COVID-19, related to numerous factors with a negative impact on the "remoted" position. Research on work engagement in a remote working mode is initially supported by Kahn, who separated the concept of engagement from psychological presence, since "physical presence is an important facet of psychological presence, physical absence does not determine psychological absence" [57]. Recent research has also noted that working from home had a negative impact on productivity and work engagement during the COVID-19 outbreak [58].

\subsection{Negative Work-Home Interaction}

Remote working during the COVID-19 pandemic encountered a specific blend of working ambience combined under forced conditions to accomplish job tasks in a home atmosphere. The recently remote workers obtained offices in their homes and family members were turned into "coworkers", usually without a voluntary agreement. Working at home in the mode of remote working actualized the importance of research on the work-home interaction in that context. Demerouti and Geurts [59] defined work-home interaction (WHI) as "a process in which one's functioning (and behavior) in one domain (e.g., home) is influenced (positively or negatively) by quantitative or qualitative demands/resources from the other domain (e.g., work)". Based on this definition, four coherent dimensions were constructed: negative work-home interaction, negative home-work interaction, positive work-home interaction and positive home-work interaction. Negative work-home interaction referred to a situation where the negative reactions related to work hinder a functioning at home, while negative home-work interaction indicated a situation where the negative load reaction established at home initiate difficulties in functioning at work [60]. The distinctive context of remote working during the COVID-19 pandemic focused attention on negative work-home interaction (NWHI) and negative home-work interaction (NHWI).

A study on the impact of work on home life among oncologists confirmed a high negative work-home interaction score, mainly due to increased productivity requirements and the need to complete administrative tasks after the end of the work day [61]. In their study, Rothmann and Baumann [62] did not register a statistically significant direct path between negative work-home interaction and employee engagement. Research on work engagement among medical residents has shown that negative work-home interaction was negatively associated with the vigor and dedication dimensions of work engagement [63]. Listau, Christensen and Innstrand [64] registered a statistically significant and negative relationship between the engagement dimension of vigor and dedication and work-home conflict. The negative statistically significant correlation between the dedication dimension of work engagement and the positive correlation between absorption dimensions of work engagement was registered in the research done by Vayre andVonthron [65], while a statistically significant correlation between the vigor dimension of work engagement wasn't noted, but was marked as negative.

The unfavorable working environment that emerged as a result of forced remote working during the COVID-19 pandemic could cause a negative work-home spillover. Ispas and Iliescu [66] argued that a negative spillover from work to family is associated with reduced mental health, anxiety and poor general physical health, mutually decreasing the potential for effectiveness at work. Recent research on the effects of negative work-home interaction during the COVID-19 quarantine revealed that NWHI was solely responsible for negative affective states [67]. This circulus vitiosus is likely be present within remote working during the COVID-19 pandemic, while focusing on negative work-home interaction as a possible a predictor of future work-related outcomes, including work engagement. A study among employees in the construction industry has shown that job demands, increased with the pressure at work, were positively related to negative work-home interaction and job resources, decreased with weak colleague and supervisor support and are negatively 
related to NWHI; negative work-home interaction is positively related to burnout [68]. Previous context is likely to be similar to the context of remote working during the COVID-19 pandemic. The positive relationship between NWHI and burnout can also be inversely interpreted as a negative relationship between negative work-home interaction and work engagement, since engagement in the workplace was described as positive antithesis of burnout. Consequently, the previous interpretation leads to the development of the hypothesis below:

Hypothesis 1 (H1). Negative work-home interaction is negatively associated with work engagement.

\subsection{Negative Home-Work Interaction}

Home-work interaction took on unique characteristics within a widespread remote working movement during the COVID-19 pandemic. Home interiors became working spaces without comprehensive adjustments or prior preparation, thus causing less working comfort for the newest remote workers. The importance of work environment is emphasized by Vischer, who offered a model comprising physical, functional and psychological comfort and suggested that a positive and supportive work environment can enhance worker commitment and performance [69]. The inadequacy of workspaces at home during remote working can affect tension and stress and high negative home-work interaction (NHWI). Additionally, research revealed that higher home demands, higher job demands and less job support were significantly associated with a higher level of negative HWI [70]. The research has shown that home-work interference or the related need for recovery is associated with impaired concentration, explained as a decreased ability to focus, having negative load effects from home to work [71]. Experiences related to balanced family interests and switching off from work in the evening facilitate recovery and enhance performance on a day-to-day basis [72]. Menges et al. [73] concluded that family support offers remarkable intrinsic motivational potential that can improve performance in the workplace.

Numerous studies have established a direct and indirect relationship between homework interaction and performance. Research among married employees stated that family demands negatively affected the job performance of female employees more than male employees, and the explanation for these outcomes was that female employees made more adjustments in their workloads regarding their family needs, refusing to do overtime work or additional tasks [74]. The research results of Demerouti, Bakker and Voydanoff [75] supported the hypothesis that home demands were predicted to negatively affect job performance through home-work interference (HWI) in the male population. Nart and Batur [76] reported a negative correlation between work-family conflict and job performance. A negative home-work interaction was negatively associated with psychological availability, which indicates readiness to perform work roles [62]. A significant relationship between family-work conflict and job performance was revealed in the sample of working mothers [77]. The research conducted by Patel et al. [78] did not register a negative relationship between family-work conflict and job performance in the sample of working mothers, explaining this by pointing to pressure resulting from awareness of financial implications caused by low performance. The results of the research have limited implications for our study because of the fact that Serbian Government financially supported companies to prevent layoffs and obligated them to return money if they reduce their workforce. The positive implication of the measures was the lower risk of job loss for most employees.

Remote working is predominantly based on ICT technology and ICT-related activities. Berkowsky's study suggested that the frequency of engaging in ICT-related activities (e.g., checking email and using Facebook) is associated with negative work/home spillover [79]. The high negative home-work interaction during the COVID-19 pandemic can be determined because remote workers do not have working conditions like in the office that are set to be exclusively subordinate to work, but work from home in conditions that mimic their office work environment. Additionally, the general lockdown has led 
remote workers to carry out their tasks in the presence of other family members, often children seeking special attention, in the presence of several distractions such as noise or the presence of other media that disturb and reduce concentration and can lead to low job performance. Consequently to this background, the following hypothesis is provided:

Hypothesis 2 (H2). Negative home-work interaction is negatively associated with job performance.

\subsection{Loneliness}

Loneliness has attracted the attention of many studies for years before the COVID-19 pandemic. With the COVID-19 outbreak and the implementation of physical distancing as a crucial social strategy to prevent the spread of COVID-19, there are new incentives and greater practical implications for academic research into loneliness. Dahlberg (2021) noted that several studies have registered increased loneliness since the outbreak of COVID-19 [80]. Kato, Sartorius and Shinfuku [81] argued that social isolation due to COVID-19 can be imposed by government restrictions and/or due to an individual's fear of infection.

Different types of relationships were noted as useful for the assuagement of loneliness: partners, daughters and sons, grandchildren, siblings and other family members, friends, colleagues and neighbors [82]. Spithoven et al. [83] defined loneliness as a negative and distressing emotional state that arises from a discrepancy between the desired and the achieved levels of social connectedness. Çolak and Çetin [84] have explained the three dimensions of loneliness: private loneliness, relational loneliness and collective loneliness. Private loneliness was referred to as an emotional loneliness, implying the perceived absence of a person who provides emotional support and mutual assistance. Relational loneliness is related to the perceived absence of a quality friendship or family relationship and is marked as social loneliness. Collective loneliness consists of a person's valued social identities within an active network group of individuals. Each noted dimension of loneliness plays an important role in the daily routine of remote workers, but most relevant to our study and generally to organizational studies is relational loneliness, related to the ties between remote workers and their colleagues and managers. Ay noted that workplace loneliness arises when an employee does not have sound relations with colleagues at work [85]. Summing up previous research, Zhou stated that both individual and organizational characteristics, such as the atmosphere of the organization and organizational support, influence workplace loneliness, while workplace loneliness is negatively related to job satisfaction, organizational commitment and job performance [86].

Due to the COVID-19 pandemic and forced remote working, the boundaries between home and work life are blurred, while loneliness and associated negative outcomes are far from an excluded research topic [87]. Lam and Lau [88] revealed that workplace loneliness was negatively and significantly related to in-role performance. Important empirical evidence comes from Ozcelik and Barsade [89] who stated that workplace loneliness had strong negative relationships with employees' performance. The study conducted by Deniz [90] also confirmed that loneliness at the workplace negatively affected employees' job performance. Recent research was found that workplace loneliness negatively affects creative performance [91]. A review of previous academic research influences us to hypothesize that:

Hypothesis 3 (H3). Loneliness is negatively associated with job performance.

Numerous studies have looked at loneliness and its effects, but limited research has provided empirical evidence of the relationship between loneliness and work engagement. The same conclusion comes from Firoz, Chaudhary and Khan [92], who have stated that the theoretical perspective on loneliness proposed numerous negative outcomes for individuals and organizations; however, the empirical validation of these theoretical assertions is still lacking, with limited empirical evidence linked to outcomes such as work engagement. 
Basit, Azeem and Haq [93] noted in their study that workplace loneliness reduces the positive and fulfilling nature of work engagement. Jung, Song and Yoon [94] stated that an employee's workplace loneliness negatively affects work engagement. Researching the mediating effect of work engagement in their study, Tian, $\mathrm{Pu}$ and Ren [95] registered a direct negative effect of workplace loneliness on work engagement. To the best of our knowledge, no studies provide empirical evidence of the impact of loneliness on work engagement in the context of remote working. Consequently, our study proposes the following hypotheses:

Hypothesis 4 (H4). Loneliness is negatively associated with work engagement.

\subsection{Social Support}

The embodied reality of remote working in the new circumstances dramatically introduced changes in the social context of individuals. For the remote workers with family, the relationship with coworkers has been substituted with family ties. The relationship of the single remote workers with their colleagues was not interchanged, which narrowed the field of their social network. The cases noted less social connection due to a cut-off in face-to-face relations with colleagues and an open field for the development of loneliness. Other side effects included a lack of face-to-face supervision, distractions at home and a lack of access to information, suggesting the need to introduce new action to ease workplace migration, such as providing opportunities for remote social interaction, encouragement and emotional support, providing several different communication technology options and the establishment of "rules of engagement" [96]. The proposed management actions are based on social support, with the end aim of sustaining readiness to perform job tasks while focusing on the negative accompanying occurrences of remote working. Eisenberger et al. [97] suggested that the social relationship induces a social exchange process in which the relationship between employees and the organization is inversely dependent.

Schwarzer, Knoll and Rieckmann [98] defined social support as the "function and quality of social relationships, such as perceived availability of help or support actually received". New ICT solutions have changed the way people practice social interaction and give the opportunity to be connected with social network members even when not present in the same social space. Thus, social networks also represent relationships established on the internet that encircle an individual together due to identification with network characteristics, such as range or size, degree of interconnection, extent of closeness such as kin, workplace, neighborhood and similarity of members [98].

The previous review indicated that it is likely that employee work-life conflict cannot be attenuated without perceived support from their organization or managers, creating a possibility for the appearance of negative work outcomes. The empirical evidence suggested that the lack of social support constructs, including a lack of support principals and a lack of support colleagues, was negatively related to perceived self-efficacy [99]. Research done by Baruch-Feldman et al. [100] suggested that social support is positively associated with productivity. Beehr et al. [101] noted that co-worker support was only weak related to job performance, but is still statistically significant. Research among hospital nurses indicated that the nurses with high social support from coworkers registered high job performance [102]. A similar study confirmed that social support from coworkers enhanced the level of job performance [103], while a study among health educators did not confirm that the social support received from coworkers and supervisors can predict job performance [104]. The research among administration staff has shown the positive and significant relationship between social support and job performance [105]. A recent study also concluded that perceived peer support is positively associated with job performance [106]. Accordance to previous academic research the following hypothesis is provided:

Hypothesis 5 (H5). Social support is positively associated with job performance. 
Schaufeli and Salanova [107] indicated that social support from colleagues and supervisors was positively related to work engagement. Bakker and Demerouti [42] designated social support as a job resource with a positive association with work engagement. The two comparable studies on engagement reported statistically significant association between daily changes in social support and work engagement $[108,109]$. The meta-analytic approach on the previous work engagement studies conducted by Halbesleben [110] reported that job resources, including social support, performance feedback and organizational climate, were significant predictors of work engagement. Recent studies have found that perceived peer support and perceived supervisory support were positively related to work engagement in nursing [106], and that organizational climate components, such as a leadership-employee relationship, is positively related to the work engagement of employees [111]. Consequently, this review leads to the development of the hypothesis below:

Hypothesis 6 (H6). Social support is positively associated with work engagement.

Ross, Altmaier \& Russell [112] revealed that job-related stress was associated with higher levels of burnout, and that social support coming from supervisors and colleagues was related to lower levels of burnout, which indicates the mediating role of the social network. However, the study did not support the buffering role of social support, while previous research did. These results had implications for our study because job-related stress can record negative work-home interaction, while burnout was described as an antipode of work engagement. Social support, embodied through a collegial relationship, with readiness to share knowledge, materials and emotional support, indicates a positive engagement experience among coworkers [113]. The suggested long-term care staff interventions to reduce burnout include a focus on stress and social support outside work [114]. The important findings come from research based on the participation of technical and information technology managers, which confirmed that supervisor support positively modified the relationship between job demands and work engagement, while this effect within colleague support was not noted [115]. According to our defined hypothesis on the relationship between work-home interaction and work engagement and the previously stated role of social support we propose:

Hypothesis 7 (H7). Social support mediates the relationship between negative work-home interaction and work engagement.

An early study on the relationship between workload and performance by Glaser et al. [116] registered the buffering role of social support, which indicated a lower level of stress when social support is high. Empirical evidence also revealed that high levels of co-worker support and non-work support under conditions of high strain were related to better levels of performance [117], and the social stressor-performance relationship was significantly influenced by social support [118]. The result of the study conducted by Foy et al. [119] registered a negative moderating effect of social support on job-related stress and a negative indirect effect of social support on the relationship between job-related stress and job performance, indicating that workers exposed to a higher level of job stress can enhance their performance if they receive social support.

A weekly diary study on the buffering role of social support revealed that job insecurity at the time of restructuring was negatively related to in-role job performance, and also found that this negative intra-individual relationship was less pronounced when employees felt supported by their supervisor [120]. The conclusion of cited research has an implication for our study because job insecurity as a result of a restructuring strategy in a time of economic crisis can be compared with downsizing during the crisis caused by the COVID19 pandemic and its relatedness to stress, while job stress and higher job demand were registered as a predictor of negative home-work interaction. Additionally, social support possesses an inherent power to mediate the relationship between negative home-work 
interactions, caused by negative work-related matter, and job performance. The transfer from office to home and widespread remote working induced an important negative impact on home-work interaction and, as is likely, to other work outcomes. Remote working during the COVID-19 outbreak faded the essentially necessary border between work and home, leading to interchangeable role duality. Simultaneously, working at home in the remote working mode and conducting home affairs during working time, which regularly appears in reality due to the presence of other family members at home during COVID-19 lockdown, created potential conflict between a remote worker and their family members. Previous research results indicated a significant moderating role of social support between role conflicts assigned to job and job performance [105] and noted that family-work conflict negatively influenced job performance [121]. Summarizing the previous review and remote worker home-work interaction, we propose the following hypothesis:

Hypothesis $\mathbf{8}$ (H8). Social support mediates the relationship between negative home-work interaction and job performance.

Interest in workplace isolation was registered considerably before remote working practices, as isolation can also occur among workers in traditional work settings; however, as the new form of work arrangement gained popularity, workplace isolation increased in relevance in academic research and management practice. Bentley et al. [122] found that the intensity of remote working and type of remote working moderated the relationship between isolation and work outcome, and registered that low-intensity remote working embodied within a few hours per week, or a hybrid remote working mode, reduces the impact of isolation on psychological strain and job satisfaction. There is a lack of research that establishes the direct moderating effects of social support on the relationship between loneliness and organizational outcomes, such as job performance and work engagement.

Studies by Eisapareh et al. [123] confirmed the moderating effect of social support, while job stress appeared as a dependent variable. The circumstances in which job stress occurs induce settings that could lead to negative work-home interaction. A study on the COVID-19-induced layoff of employees in the hospitality industry revealed the positive moderating role of social support between COVID-19-related stress and performance [124]. However, workplace loneliness was negatively and significantly related to in-role performance [88], and negatively affected creative performance, while psychological capital positively buffered the relationship between workplace loneliness and creative performance [91]. Zhou and Lin [125] have argued that social support can result in or promote positive psychological outcomes, while a study by Yang and Wen [126] revealed that a sense of humor in leaders resulted in a lower workplace loneliness climate and, thus, better team performance.

A study on administrative sector employees involved in the reorganizational process confirmed the positive moderating effect of social support on the relationship between concerns about mastering change and work engagement [127]. The sense of concern caused by the reorganizational process is not equal with the sense of loneliness caused by the COVID-19 pandemic and therefore remote working, but there are parallels, as both refer to the psychological state of individuals induced by external factors. Socially supportive ties have clear benefits in times of stress because individuals can control their emotional responses to stressful situations, which can be translated into mental and physical health benefits [128], creating better work outcomes. Dahlberg [80] noted that many interventions to reduce loneliness are based on group activities, the implementation of which is not given in the usual face-to-face procedure, but can be replaced with new social interaction tolls based on ICT. With the esteem of the previous review, and our earlierdefined hypothesis on loneliness, our study hypothesized that social support significantly moderates the relationship between loneliness and work-related outcomes within remote working circumstances. 
Hypothesis 9 (H9). Social support moderates the relationship between loneliness and job performance.

Hypothesis 10 (H10). Social support moderates the relationship between loneliness and work engagement.

\subsection{Originality of the Research}

Previous studies have already been concerned with the direct relationship between negative work-home interaction, negative home-work interaction, loneliness and social support as independent variables and job performance and work engagement as dependent variables, mostly but not particularly from an integrated perspective. Additionally, in various studies, social support emerged as a moderator and mediating variable for work outcomes and related context. In the study, social support has been considered as a function of job performance and work engagement within the context of remote working during the COVID-19 pandemic, and a buffer for possible negative effects of home-work interaction, work-home interaction and loneliness. To the best of our knowledge, the integrated view of the defined variables has not been presented in the existing studies, particularly concerning remote work practice and the Serbian context.

\section{Methodology}

\subsection{Participants and Procedure}

The sampling procedure was conducted using a convenience sampling method, with a focus on the companies that practiced a remote work mode for most of their current jobs. A total of 305 questionnaires were distributed to employees with remote working status in companies in different sectors (private and public) and diverse industries that operated within the Serbian economy during the COVID-19 pandemic. Regarding the ethical approval process, all participants were fully informed about the academic purpose of the study. The respondents were assured of anonymity, which was additionally explained with the web-based approach. Additionally, we guaranteed to the participants that demographic data will be only used for statistical analysis and that the data will never be accessible to third parties. The participants were kindly asked to take a part in a survey, but absolutely according to their will and the time available to them. The study was designed to focus on remote workers. Therefore, we first contacted HR managers, senior managers and executive managers to provide only the respondents with remote working status. Only these employees were contacted, and 226 valid questionnaires were ultimately collected. The procedure for electronic surveys proposed by Klassen and Jacobs [129] was followed. Invitations to the participants were distributed by email with a link to the web-based survey questionnaire. Additional follow-up reminder emails were sent twice, two weeks after and four weeks after the initial call, to increase the response rate. The participants were encouraged to contact us if they needed support or had doubts regarding the survey. The employees with remote working status were engaged in jobs that could be done remotely using ICT and software provided by companies, such as marketing, logistics, administration, sales, purchasing, training and education. This supplied additional relevant data, assuring us of the employees' status of remote working. The respondents were working in diverse industries, such as automotive, food and drink, wholesale, transport and education.

The respondents were also asked questions about their demographics, such as gender, age and level of education. Most of the respondents were female, at 57 percent, while 43 percent were male. Most of the sample consisted of respondents aged between 31 and 40 years, followed by those aged between 41 and 50 years, those aged less than 30 years and those aged more than 50 years, with 46 percent, 26 percent, 15 percent and 13 percent, respectively. The respondents with a high level of education (graduates and those with master's degrees) were dominant in the sample, at 83 percent (48 percent and 35 percent, respectively). A diversity of participants was achieved in the study, and is likely to have offered a better understanding of the results and generalization of the findings. 
To prevent the common method bias problem, we followed several recommendations proposed by Podsakoff et al. [130]. Firstly, respondents were assured of the anonymity and confidentiality of their responses and that they would be used for academic purposes only. Secondly, the preamble of the starting section gave instructions on how to complete the questionnaire. Thirdly, in the questionnaire, the sections within items of independent variables (antecedents) were separated from the sections within items of dependent variables (outcomes).

\subsection{Measurements}

To test the proposed hypotheses, we used a structured questionnaire to conduct research. The questionnaire was divided into three different sections. The independent variable items were placed in the first section, followed by the constructs of the dependent variables. Both sections contained columns with the form of rating scales. Demographic details of respondents, including age, gender and level of education, were positioned in the third and last section of the questionnaire.

We used standardized measurement scales to observe the state of the selected items for the proposed variables. In accordance with the arguments of Amankwaa, Gyensare and Susomrith [131] we argued that specially designed constructs tested in previous studies are useful for our research because of their predictive value. Additionally, these scales, which have been verified in numerous studies, can indicate appropriate psychometric properties. The items in the study survey were originally written in English. We translated these scales to Serbian, and adapted their measurements to fit the Serbian context. Pretests were used within a sample of 30 respondents to obtain the required validity of instrument and the feedback regarding alternative wording if necessary. The participants rated all items on a five-point Likert scale in the format settled on, from "strongly disagree" (indicated by 1) to "strongly agree" (indicated by 5). The following measurement scale was used for the study:

Work Engagement. We measured this construct with the four items developed in the well-known Utrecht Work Engagement Scale (UWES) scale [132]. Deployed items represented the dedication scale of a UWES survey, for example, "I am enthusiastic about my job" and "My job inspires me". The results of a study by Petrović, Vukelić and Čizmić [133] confirmed that the Serbian versions of UWES have satisfactory psychometric properties with high reliability and good predictive validity.

Job performance. This construct was observed with three items, such as: "I adequately completed my assigned duties", "Fulfills responsibilities specified in job description" and "Performs tasks that are expected of him/her", segregated from the job performance scale developed by Williams and Anderson [134] and already used in studies related to remote working [33].

Negative work-home interaction. Perception of this construct was measured with a prominent Survey Work-home Interaction / Nijme Gen (SWING) scale [135]. The study included six items, such as "You find it difficult to fulfil your domestic obligations because you are constantly thinking about your work" and "You do not fully enjoy the company of your spouse/family/friends because you worry about your work".

Negative home-work interaction. The same SWING scale items [135] were deployed for measuring negative home-work interaction. The construct was defined with four items, such as "You do not fully enjoy your work because you worry about your home situation" and "You have difficulty concentrating on your work because you are preoccupied with domestic matters".

Loneliness. A respondent's perception about loneliness was measured using three items of the reputable UCLA loneliness scale [136]. The loneliness construct consisted of the following items: "I lack companionship", "I did feel alone" and "I felt isolated from others".

Social support. We measured this construct with the items from the notable Work Design Questionnaire (WDQ) scale [137]. Three items were used: "People I work with 
are friendly", "I have the opportunity to develop close friendships in my job" and "My supervisor is concerned about the welfare of the people that work for him/her".

\section{Results and Analysis}

The hypotheses defined in the study were tested using the partial least square approach to structural equation modeling (PLS-SEM). Hair et al. [138] suggested that variance-based SEM expresses excellence in dealing with complex models and non-normally distributed data. Thus, we decided to use a variance-based approach with PLS-SEM instead of the covariance-based SEM, as our study has a certain complexity due to the assumed mediating and moderating effects, and the preliminary analysis has shown that the research method does not meet the criteria of normality. The additional argument for using the PLS-SEM approach is based on the inherent characteristic of the research, as it is related to management concepts and human resource management, and both are well supported by the named method $[139,140]$. The two-step approach was implemented after preliminary results for the validation of the measurement model and for assessing the structural model quality, as proposed by Anderson and Gerbing [141]. To prepare the data for the partial least square approach to the structural equation modeling, we have used SPSS v.23 package before engaging SmartPLS 3.0 software to take the relevant indicators of the reflective measurement model into account.

The study included a total of six key constructs related to the remote working context during the COVID-19 pandemic, such as negative work-home interaction (NWHI), negative home-work interaction (NHWI), loneliness (LO), social support (SS), work engagement (WE) and job performance (JP). The results presented in Figure 1 revealed that the negative work-home interaction was negatively related to work engagement $(\beta=-0.15, p<0.05)$, while negative home-work interaction did not register an association with job performance. Loneliness is negatively related to work engagement $(\beta=-0.22, p<0.001)$ and is not related to job performance. Social support is positively associated with work engagement $(\beta=0.55, p<0.001)$ and job performance $(\beta=0.45, p<0.001)$.

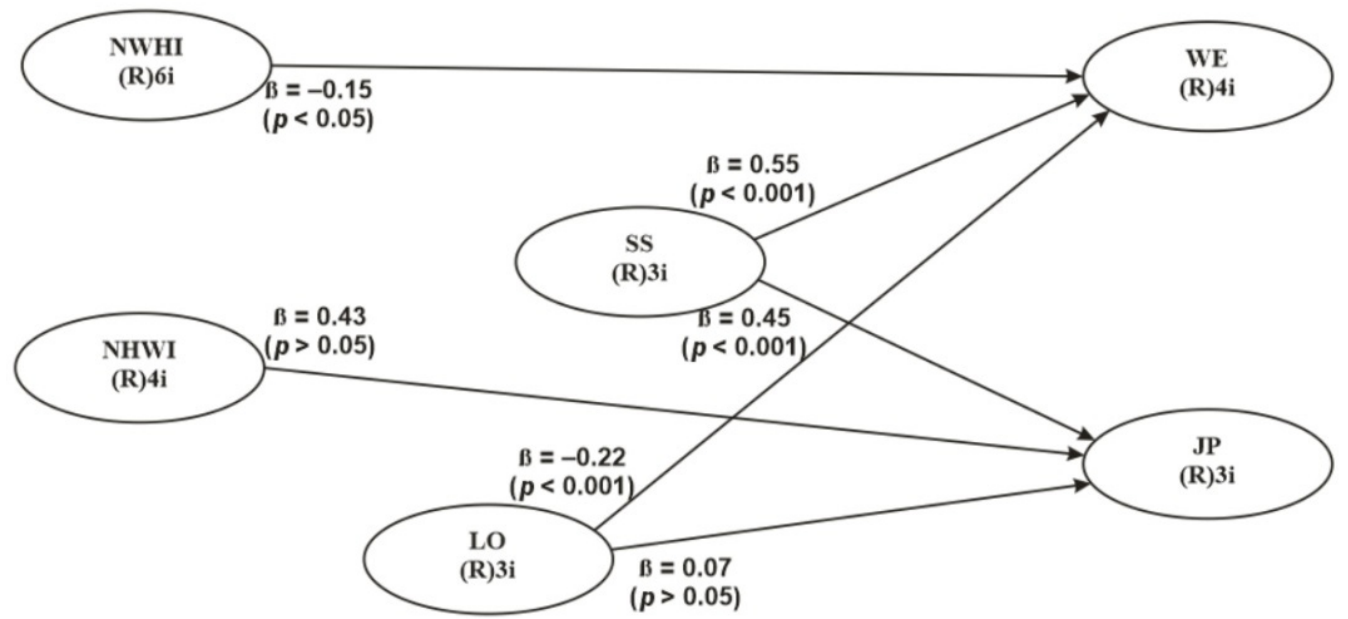

Figure 1. SEM-PLS path modelling.

\subsection{Measurement Model Assessment}

A confirmatory factor analysis was performed for the proposed constructs in order to test their reliability and validity. The results of the internal consistency reliability and the convergent validity analysis of the proposed model are presented in Table 1 . The Cronbach's alpha coefficient showed a value above the acceptable threshold for all latent variables [142]. Hair et al. [143] suggested 0.7 as a restrain value for composite reliability (CR), and each construct of the study was above these measures. The noted indicators suggested that the measurement model of our study indicates good internal consistency. The convergent validity is measured by AVE (Average variance Extracted) within a desired 
value greater than 0.5 , which explains that the construct represents more than $50 \%$ of the variance of its items $[144,145]$. For all constructs, the AVE is listed between 0.592 and 0.775 and meets the required criteria.

Table 1. Measurement model and constructs.

\begin{tabular}{|c|c|c|c|c|c|c|}
\hline Construct and Items & Loadings & VIF & CR & $\alpha$ & AVE & $\begin{array}{c}\text { Cross-Validated } \\
\text { Communality Index }\left(\mathbf{H}^{2}\right)\end{array}$ \\
\hline $\begin{array}{c}\text { NWHI: Negative } \\
\text { work-home interaction }\end{array}$ & & & 0.903 & 0.927 & 0.631 & 0.599 \\
\hline NWHI01 & 0.955 & 1.572 & & & & \\
\hline NWHI02 & 0.824 & 3.411 & & & & \\
\hline NWHI03 & 0.707 & 4.237 & & & & \\
\hline NWHI04 & 0.556 & 3.961 & & & & \\
\hline NWHI05 & 0.674 & 4.328 & & & & \\
\hline NWHI06 & 0.519 & 3.750 & & & & \\
\hline $\begin{array}{c}\text { NHWI: Negative } \\
\text { home-work interaction }\end{array}$ & & & 0.879 & 0.880 & 0.658 & 0.550 \\
\hline NHWI01 & 0.837 & 1.964 & & & & \\
\hline NHWI02 & 0.598 & 2.240 & & & & \\
\hline NHWI03 & 0.980 & 2.937 & & & & \\
\hline NHWI04 & 0.639 & 2.216 & & & & \\
\hline LO: Loneliness & & & 0.866 & 0.867 & 0.687 & 0.544 \\
\hline LO01 & 0.907 & 1.866 & & & & \\
\hline LO02 & 0.649 & 2.701 & & & & \\
\hline LO03 & 0.905 & 3.258 & & & & \\
\hline SS: Social support & & & 0.812 & 0.810 & 0.592 & 0.436 \\
\hline SS01 & 0.679 & 1.653 & & & & \\
\hline $\mathrm{SS} 02$ & 0.811 & 2.096 & & & & \\
\hline SS03 & 0.812 & 1.770 & & & & \\
\hline WE: Work engagement & & & 0.896 & 0.897 & 0.684 & 0.587 \\
\hline WE01 & 0.872 & 2.740 & & & & \\
\hline WE02 & 0.830 & 3.013 & & & & \\
\hline WE03 & 0.865 & 2.270 & & & & \\
\hline WE04 & 0.734 & 2.564 & & & & \\
\hline JP: Job performance & & & 0.912 & 0.911 & 0.775 & 0.654 \\
\hline JP01 & 0.865 & 3.079 & & & & \\
\hline JP02 & 0.871 & 3.271 & & & & \\
\hline JP03 & 0.904 & 2.962 & & & & \\
\hline
\end{tabular}

Collinearity statistics measured by VIF (variance inflation factor) represent values above 5 for all items, and indicate that multi-collinearity does not pose a problem in the measurement model. The cross-validated communality index $\left(\mathrm{H}^{2}\right)$ is ranged from 0.436 to 0.654 and demonstrates positive values for all latent variables as it was required. The discriminant validity was validated within the heterotrait-monotrait (HTMT0.85) criterion proposed by Henseler et al. [146]. The results presented in Table 2 show that the values are below the 0.850 marked as the maximum value, confirming that our measurement model matches satisfactory discriminant validity. 
Table 2. Discriminant validity (HTMT0.85 criterion).

\begin{tabular}{ccccccc}
\hline Constructs & $\mathbf{1}$ & $\mathbf{2}$ & $\mathbf{3}$ & $\mathbf{4}$ & $\mathbf{5}$ \\
\hline $\begin{array}{c}\text { 1. NWHI: Negative work-home } \\
\text { interaction }\end{array}$ & - & & & & \\
2. NHWI: Negative home-work & 0.709 & & & & \\
$\quad$ interaction & 0.423 & 0.448 & & & \\
3. LO: Loneliness & 0.149 & 0.451 & 0.146 & & & \\
4. SS: Social support & 0.298 & 0.409 & 0.364 & 0.578 & & \\
5. WE: Work engagement & 0.105 & 0.301 & 0.064 & 0.687 & \\
6. JP: Job performance & & & & \\
\hline
\end{tabular}

\subsection{Structural Model Assessment}

The assessment of the structural model was initiated with the blindfolding option in PLS-SEM. The cross validated redundancy index (Stone-Geisser $\mathrm{Q}^{2}$ ) was calculated for the endogenous latent variable to assess the predictive relevance. The values of $\mathrm{Q}^{2}$ were calculated as $0.121,0.248$, and 0.291 for social support, work engagement and job performance, respectively. Positive $\mathrm{Q}^{2}$ values were indicated as acceptable, which suggests the goodquality of the structural model $[147,148]$. The coefficient of determination of the explained variance $\left(R^{2}\right)$ was evaluated for the observed constructs. The resulting values of $R^{2}$ report that 12.1 percent of social support, 24.8 percent of work engagement and 29.1 percent of job performance provide a relatively high level of the model's explanatory power. The standardized root mean square residual (SRMR) proposed by Henseler et al. [149] is used to avoid model misspecification. The value of SRMR for the model was 0.06 and is necessarily below the 0.08 criterion recommended by $\mathrm{Hu}$ and Bentler [150]. The goodness-of-Fit (GOF) was calculated manually for all dependent and intermediate variables as the root square of the multiplication of communality and $\mathrm{R}^{2}$. The values presented in Table 3 indicated that GOF values for social support, work engagement and job performance were in the acceptable range of $0-1$.

Table 3. Structural model fit indicies.

\begin{tabular}{cccc}
\hline Construct & Stoner-Geisser $\mathbf{Q}^{\mathbf{2}}$ & $\mathbf{R}^{\mathbf{2}}$ & $\mathbf{G O F}$ \\
\hline Social Support & 0.121 & 0.179 & 0.147 \\
Work engagement & 0.248 & 0.326 & 0.284 \\
Job performance & 0.291 & 0.346 & 0.317 \\
SRMR & 0.06 & & \\
\hline
\end{tabular}

The standard PLS-SEM bootstrapping procedure was launched to determine the magnitude and significance of the path coefficients. The bootstrapping was used to calculate the two-sided bi-as-corrected 95 percent confidence intervals (CIs) for each relation determined within the hypotheses, and to evaluate indirect effects. The structural model results, lower and upper CIs and hypotheses tested on direct effects are reported in Table 4. Statistical analysis indicated that negative work-home interaction (NWHI) is negatively related to work engagement (WE) $(\beta=-0.151, p<0.05)$, and therefore the hypothesis H1 is supported. The results revealed that negative home-work interactions (NHWI) are negatively associated with job performance (JP), but not in a statistically significant way, as well as the relationship between loneliness (LO) and job performance. Thus, the conclusion is that the hypotheses $\mathrm{H} 2$ and $\mathrm{H} 3$ aren't supported. Loneliness recorded a negative relationship with work engagement $(\beta=-0.215, p<0.001)$, which suggests the acceptance of hypothesis H4. Additionally, a one-point increase in perceived loneliness would decrease work engagement by 0.215 points. The results of the study supported both hypotheses $\mathrm{H} 5$ and $\mathrm{H} 6$, as social support (SS) is positively associated with job performance $(\beta=0.551, p<0.001)$ and work engagement $(\beta=0.488, p<0.001)$. Hence, empirical evidence indicated that the one-point increase in social support would increase job performance by 0.551 points and 
increase work engagement by 0.488 points, suggesting a strong predictive impact on the stated outputs.

Table 4. Results of testing the hypothesis: direct effects.

\begin{tabular}{cccccc}
\hline Relationship & Path Coefficient & t-Value & 95\% CIs (Bias Corrected) & Hypothesis & Results \\
\hline NWHI $\rightarrow$ WE & $-0.151^{*}$ & 2.346 & {$[-0.279,-0.028]$} & H1 & Supported \\
NHWI $\rightarrow$ JP & -0.116 & 1.799 & {$[-0.248,0.005]$} & Hot supported & Not supported \\
LO $\rightarrow$ JP & 0.067 & 1.116 & {$[-0.042,0.193]$} & H3 & Supported \\
LO $\rightarrow$ WE & $-0.215^{* * *}$ & 3.490 & {$[-0.330,-0.094]$} & H5 & Supported \\
SS $\rightarrow$ JP & $0.551^{* * *}$ & 9.802 & {$[0.426,0.649]$} & H6 & Supported \\
SS $\rightarrow$ WE & $0.448^{* * *}$ & 8.072 & {$[0.341,0.563]$} &
\end{tabular}

Notes: NWHI, negative work-home interaction; NHWI, negative home-work interaction; LO, loneliness; SS, social support; JP, job performance; WE, work engagement. ${ }^{*} p<0.05 ;{ }^{* * *} p<0.001$.

To test the mediating and moderating role of social support in our model, we followed procedure proposed by Zhao et al. [151]. The bootstrap results of the indirect effects are presented in Table 5. A statistically significant indirect effect and positive relationship between negative work-home interaction and work engagement through social support was revealed $(\beta=0.088, t=2.252, p<0.05)$. Indirect effects within a negative prediction were found between the negative home-work interaction and job performance through social support $(\beta=-0.297, t=5.293, p<0.001)$. The evidence for direct effects provided more insight on the mediator effect in our model [152]. Regularly, the partial mediating role of social support is confirmed between negative work-home interaction and work engagement due to a statistically significant direct association between these constructs. The direct association between negative home-work interaction and job performance was not registered, while the full mediating effect of social support between negative homework interaction and job performance was revealed. Thus, both hypotheses $\mathrm{H} 7$ and $\mathrm{H} 8$ were confirmed and induced the buffering role of social support.

Table 5. Results of testing the hypothesis: indirect effects.

\begin{tabular}{cccccc}
\hline Relationship & Path Coefficient & t-Value & $\mathbf{9 5 \%}$ CIs (Bias Corrected) & Hypothesis & Results \\
\hline NWHI $\rightarrow$ SS $\rightarrow$ & $0.088^{*}$ & 2.252 & {$[0.014,0.164]$} & H7 & Supported \\
WE & $-0.297^{* * *}$ & 5.293 & {$[-0.407,-0.191]$} & H8 & Supported \\
NHWI $\rightarrow$ SS $\rightarrow$ JP & $-0.166^{* * *}$ & 3.239 & {$[-0.255,-0.059]$} & H9 & Supported \\
$\begin{array}{c}\text { Moderation LO } \rightarrow \\
\text { SS } \rightarrow \text { JP }\end{array}$ & -0.049 & 0.898 & {$[-0.157,0.060]$} & H10 & Not supported \\
$\begin{array}{c}\text { Moderation LO } \rightarrow \\
\text { SS } \rightarrow \text { WE }\end{array}$ & & & &
\end{tabular}

Notes: NWHI, negative work-home interaction; NHWI, negative home-work interaction; LO, loneliness; SS, social support; JP, job performance; WE, work engagement. ${ }^{*} p<0.05$; ${ }^{* *} p<0.001$.

The standard moderation procedure implemented with SmartPLS software and biascorrected bootstrapping analysis at 95\% CI to test hypotheses H9 and H10. A statistically significant moderating role of social support was presented in the relationship between loneliness and job performance $(\beta=-0.166, t=3.239, p<0.001)$, suggesting that hypothesis $\mathrm{H} 9$ is accepted, while hypothesis H10 was not supported due to the lack of statistically significant relevance.

According to the results of the direct effects and the registered indirect effects, we concluded that our study supports the mediating role of social support between negative work-home interaction and work engagement, and between negative home-work interaction and job performance, as well as the moderating role of these constructs for loneliness and job performance interaction. 


\section{Discussion}

The study investigated the impact of negative work-home interaction, negative homework interaction and loneliness perception on work engagement and job performance in remote workers who are employed in different industries in Serbia during the COVID-19 pandemic, as well as the mediating-moderating role of social support in the relationship between noted predictors and outcomes related to jobs. Due to the specific context of remote working during the COVID-19 outbreak, the hypothesized relationship offers background for a fine-grained understanding of the theoretical background and proposes managerial actions and implications.

Previous studies have shown that negative work-home interaction is negatively related to work engagement $[63,64]$. The result of the study confirmed the negative effect of the negative work-home interaction on work engagement, within remote working. The deployed measurement scale confirmed that the dedication dimension of work engagement would decrease with high negative work-home interaction caused by remote working. Contrary to research that registered a negative relationship between negative home-work interaction and job performance [76], and to our own expectations, the negative homework interaction did not note a statistically significant relation with the job performance of remote workers. This outcome is not isolated, and the absence of negative implications for the effect of negative home-work interactions on job performance was already noted [78], and was related to the context of high tension as part of retaining a job, thought is effect has not been revealed in the circumstance of remote working. The advent of remote working during the COVID-19 pandemic produced uncertainty of employment and more tension for workers to maintain their performance with the aim of keeping their jobs safe. Loneliness registered a negative influence on job performance $[89,91]$ and work engagement $[93,95]$, while the negative impact of loneliness within remote working was expected. The study noted a negative effect on work engagement, but the negative effect on job performance was not confirmed. These results lead to the conclusion that loneliness, as an internal psychological state, recorded an association with engagement rather than performance because engagement is more of a psychological construct than job performance. As expected, social support for remote workers was positively related to work engagement and job performance, in accordance with previous research $[105,106]$. Social support played a positive mediating role in the relationship between negative work-home interactions and work engagement, also demonstrating its buffering role and its capacity to turn a negative direct effect between constructs and positive associations. The same effect was expected for another hypothesized relationship. The result revealed the full mediating role of social support in the relationship between negative home-work interaction and job performance, but with a negative amplitude, suggesting that a high negative home-work interaction would imply lower job performance of remote workers if they received social support. The previous studies also noted this effect [121] and argued that support can cause more awareness of high negative home-work interactions. A similar notation can explain the moderation role of social support between loneliness and job performance relation. More perceived social support in the context of remote working during the COVID-19 was realized using ICT tools, retaining active ties with others but without real physical contact, leaving a psychological sense of distance. Taylor [128] argued that social relationships are inherently double-edged and so ties with others are not inevitably supportive. Additionally, Lam and Lau [88] noted that lonely employees were less willing to engage in social exchanges because they may have been worried that their extra efforts would not be reciprocated. Thus, social support actions need to be well planned to obtain the expected effects, while social support through the internet does not offer adequate replacement for physical presence.

The role of social support in the context of remote work also depends on the modality of social support itself and the factors involved. Managing and preserving the social construction has been noticed as a serious challenge, as it needs to be transformed having been engrained in co-located work environments [153]. The social construction established 
with colleagues in the physical workplace was not easily carried over to the remote working relationship configured during the COVID-19 outbreaks. These implied that the quality of social support can differ between regular working and remote working, with the indication that the lowest effectiveness was presented in the remote working mode. In relation to our study, this could explain the lack of a buffer effect in social support in some relations, especially if the effect remains negative. The newly induced remote workers simply compare social support and constitute a unique personal sense of received social support during work from home. The modified perception of received social support also depends on the way the managers provide it. [154] argued that managers have a negative attitude toward remote working and feel the performance of remote workers is comparatively lower than those who work in the office. Instead of delivering social support, managers primarily worked on monitoring and controlling activities of remote workers to sustain job performance. Therefore, social support was subtly substituted with more workload, which leads to improved performance but also to negative side effects. The hidden transformation of social support defeats its primary role and annuls its positive buffer effects, but sustains job performance and work engagement. The above-mentioned transformation of social support finds support in our research because it reveals a mediating and moderating role, thought the effects remain negative in the relationship between negative home-work interaction and job performances as well as between loneliness and job performances. The risk of a negative transformation of social support also appears when managers and supervisors are able view a lot of the details of remote workers' homes and their related arrangements, such as private pictures, hobbies or private data [155]. This sense of losing privacy could lead to social distancing, even if the social support is adequate and was previously perceived as valuable. More effort in social support, then, would be negative rather than positive.

\section{Limitations and Recommendations for Future Research}

The limitations of our study arise for two reasons. First, diversity of the participants in the study was obtained, but the homogeneity of the sample was also accepted, equivocating the "new" remote workers with employees who regularly work remotely, even before the COVID-19 outbreak. Under normal circumstances, the remote working mode is not widely accepted by organizations in Serbia, so we believe that the sample structure was not a problem, especially due to the sampling procedure, but future research would reveal differences between participants with or without prior remote working experience. Second, the context for remote working during the COVID-19 pandemic was unique and was closer to a crisis rather than a regular circumstance. Thus, generalizing statements about the widespread use of remote working, which offers cost-cutting opportunities for organizations and related outcomes, requires a longitudinal data set for more insight in to the sustainability of this organization.

Additional opportunities for future research lie in other antecedents of remote working, such as self-efficiency. This construct comes primarily from personal attitudes that are not related to the social context and at the same time reduce the need for social support to achieve satisfactory work outcomes. The weight of such factors especially rises in the context of work-home interaction. The simultaneous analysis of the impact of social support and self-efficiency would imply more insight for work outcome prediction. The possibility of social support can be used as an "invisible" shield for an increased workload assigned by managers during remote working, verifying the presence of burnout effects in such circumstances. Finally, our study, like many others, was focused on the benefits of remote working for firms, while positive outcomes for remote workers were subordinated. Recent research on remote working has highlighted the importance of human safety and wellbeing [156]. Thus, the future integrated study of compared benefits for both the company and remote workers is possible. 


\section{Conclusions}

Remote working became the predominant form of work during the COVID-19 outbreak, in order to continue business and promote the health of workers by maintaining social distance. Due to the ongoing COVID-19 pandemic, the massive use of remote working has prompted academics to pay more attention to this phenomenon and its related context. The aim is to provide a more theoretical and practical implication of remote working, which is of extraordinary importance for the sustainability of organizations. Our study found that negative work-home interaction, negative home-work interaction and loneliness were significant predictors of outcomes such as job performance and work engagement particularly. Social support demonstrated an important role due to its high prediction of job performance and work engagement across the direct effect and the mediating and moderating roles between predictors named in the study and outcomes. The results revealed that social support established using ICT solutions would record benefits, but also would not be a perfect substitute for social support received through physical contact. Hence, the previous discussion induced the conclusion that social support via ICT solutions would record benefits for an organization due to positive effects on job performance and work engagement, but only as a short-term strategy due to an inability to revert the negative antecedents of remote working, such as negative home-work interaction and loneliness. This conclusion can to be considered in the context of the characteristics of the national culture, especially in the collectivism vs. individualism category. The lower interchangeability between social support established via ICT solution and social support received through physical contact implies that remote working practice needs to be further observed as it has implications for an organization's sustainably.

Institutional framework conditions were identified as an important factor for sustainable remote working [157]. Within the more predictive remote working conditions based on law and related legal documents, there are less possibilities for negative work-home interaction, which can result in less need for social support for remote workers, even in a time of crisis like the COVID-19 outbreak. Important managerial implications of the study suggested that social support positively influences job performance and work engagement, but managers and supervisors tend to convert social support intent into a greater workload to achieve desired work outcomes. Job performance and work engagement would be ensured through social support for remote workers. Despite the positive outcomes, this informal substitution of social support has a negative side effect, while general managers must pay attention to the behavior of the subordinate managers. The fear of underperformed tasks while working remotely suggests that training for managers and supervisors as well as newly remote workers is needed to achieve a balance between the positive effects of social support and the potential negative effects of a substituted role. The other practical implication was partially derived from that previously noted, and implies that social support needs to be monitored and adjusted by higher-level managers, especially because recent studies recorded fewer negative effects related to the fear of the COVID-19 lockdown over time [158]. Remote-working overtime induced adjustments in employees' behavior, with a tendency towards self-regulated balance between work and home in the remote workers, and related outcomes for the company and individuals. Because of this intense manner of social support, it would be changed over time to keep drawing positive effects.

Author Contributions: Conceptualization, M.S. and S.S.; methodology, M.S. and M.B.; validation, M.S.; formal analysis, M.S. and M.B.; investigation, M.S. and S.S.; resources, M.S. and S.S.; data curation, S.S.; writing — original draft preparation, M.S. and S.S.; writing—review and editing, M.S. and M.B.; visualization, M.B.; supervision, M.S.; project administration, M.B. All authors have read and agreed to the published version of the manuscript.

Funding: This research received no external funding.

Institutional Review Board Statement: Not applicable. 
Informed Consent Statement: Informed consent was obtained from all subjects involved in the study.

Data Availability Statement: Not applicable.

Conflicts of Interest: The authors declare no conflict of interest.

\section{References}

1. Šantić, D.; Antić, M. Serbia in the time of COVID-19: Between "corona diplomacy", tough measures and migration management. Eurasian Geogr. Econ. 2020, 61, 546-558. [CrossRef]

2. Beraha, I.; Đuričin, S. The impact of COVID-19 crisis on medium-sized enterprises in Serbia. Econ. Anal. 2020, 53, 14-27. [CrossRef]

3. Adžić, S.; Al-Mansour, J. The Negative Impact of COVID-19 on Firms: Insights from Serbia. East. Eur. Econ. 2021, 59, 1-15. [CrossRef]

4. Margherita, A.; Heikkil̈̈, M. Business Continuity in the COVID-19 Emergency: A Framework of Actions Undertaken by World-Leading Companies. Bus. Horiz. 2021, 64, 683-695. [CrossRef]

5. Howe, D.C.; Chauhan, R.S.; Soderberg, A.T.; Buckley, M.R. Paradigm shifts caused by the COVID-19 pandemic. Organ. Dyn. 2020, 100804, 1-9. [CrossRef]

6. Baruch, Y.; Nicholson, N. Home, sweet work: Requirements for effective home working. J. Gen. Manag. 1997, 23, 15-30. [CrossRef]

7. Kowalski, K.B.; Swanson, J.A. Critical success factors in developing teleworking programs. Benchmarking Int. J. 2005, 12, 236-249. [CrossRef]

8. Kniffin, K.M.; Narayanan, J.; Anseel, F.; Antonakis, J.; Ashford, S.P.; Bakker, A.B.; Vugt, M.V. COVID-19 and the workplace: Implications, issues, and insights for future research and action. Am. Psychol. 2021, 76, 63-80. [CrossRef]

9. Phillips, S. Working through the pandemic: Accelerating the transition to remote working. Bus. Inf. Rev. 2020, 37, 129-134. [CrossRef]

10. Barsness, Z.I.; Diekmann, K.A.; Seidel, M.D.L. Motivation and opportunity: The role of remote work, demographic dissimilarity, and social network centrality in impression management. Acad. Manag. J. 2005, 48, 401-419. [CrossRef]

11. Bloom, N.; Liang, J.; Roberts, J.; Ying, Z.J. Does working from home work? Evidence from a Chinese experiment. Q. J. Econ. 2015, 130, 165-218. [CrossRef]

12. Elshaiekh, N.E.M.; Hassan, Y.A.A.; Abdallah, A.A.A. The Impacts of Remote Working on Workers Performance. In Proceedings of the 2018 International Arab Conference on Information Technology (ACIT), Werdanye, Lebanon, 28-30 November 2018; IEEE: Piscatway, NJ, USA, 2018; pp. 1-5. [CrossRef]

13. Staples, D.S. A study of remote workers and their differences from non-remote workers. J. Organ. End User Comput. 2001, 13, 3-14. [CrossRef]

14. Dockery, A.M.; Bawa, S. Is working from home good work or bad work? Evidence from Australian employees. Aust. J. LabourEcon. 2014, 17, 163-190.

15. Troup, C.; Rose, J. Working from home: Do formal or informal telework arrangements provide better work-family outcomes? Community Work. Fam. 2012, 15, 471-486. [CrossRef]

16. Kylili, A.; Afxentiou, N.; Georgiou, L.; Panteli, C.; Morsink-Georgalli, P.Z.; Panayidou, A.; Fokaides, P.A. The role of remote working in smart cities: Lessons learnt from COVID-19 pandemic. Energy Sources Part A Recovery Util. Environ. Eff. 2020, 14, 1-16. [CrossRef]

17. Borkovich, D.J.; Skovira, R.J. Working from home: Cybersecurity in the age of COVID-19. Issues Inf. Syst. 2020, 21, 234-246. [CrossRef]

18. Ahmad, T. Corona Virus (COVID-19) Pandemic and Work from Home: Challenges of Cybercrimes and Cybersecurity. 2020. Available online: https:/ / ssrn.com/abstract=3568830 (accessed on 27 September 2021).

19. International Labour Organisation: An Employers' Guide on Working from Home in Response to the Outbreak of COVID-19. 2020. Available online: https://www.ilo.org/actemp/publications/WCMS_745024/lang--en/index.htm (accessed on 10 October 2021).

20. Moore, J. Homeworking and work-life balance: Does it add to quality of life? Eur. Rev. Appl. Psychol. 2006, 56, 5-13. [CrossRef]

21. Allen, T.D.; Golden, T.D.; Shockley, K.M. How effective is telecommuting? Assessing the status of our scientific findings. Psychol. Sci. Public Interest 2015, 16, 40-68. [CrossRef]

22. Anderson, D.; Kelliher, C. Enforced remote working and the work-life interface during lockdown. Gend. Manag. Int. J. 2020, 35, 677-683. [CrossRef]

23. Russell, H.; O'Connell, P.J.; McGinnity, F. The impact of flexible working arrangements on work-life conflict and work pressure in Ireland. Gend. Work. Organ. 2009, 16, 73-97. [CrossRef]

24. Sullivan, C. Remote working and work-life balance. In Work and Quality of Life; Springer: Dordrecht, The Netherlands, 2012; pp. 275-290. [CrossRef]

25. Battiston, D.; Blanesi Vidal, J.; Kirchmaier, T. Is Distance Dead? Face-to-Face Communication and Productivity in Teams; Centre for Economic Performance, London School of Economics and Political Science: London, UK, 2017.

26. Morikawa, M. COVID-19, Teleworking, and Productivity, VoxEU.org 2020. Available online: https://voxeu.org/article/covid-19 -teleworking-and-productivity (accessed on 24 October 2021). 
27. Dryselius, A.; Pettersson, J. Motivation in the Remote Workplace: Understanding the Threats and Opportunities to Motivation During Enforced Remote Work; Kth Royal Institute of Technology School of Industrial Engineering and Management: Stockholm, Sweden, 2021.

28. Ajzen, I. Attitudes, traits, and actions: Dispositional prediction of behavior in personality and social psychology. Adv. Exp. Soc. Psychol. 1987, 20, 1-63. [CrossRef]

29. Moscoso, S.; Salgado, J.F. “Dark side” personality styles as predictors of task, contextual, and job performance. Int. J. Sel. Assess. 2004, 12, 356-362. [CrossRef]

30. Salgado, J.F.; Otero, I.; Moscoso, S. Cognitive reflection and general mental ability as predictors of job performance. Sustainability 2019, 11, 6498. [CrossRef]

31. Baker, E.; Avery, G.C.; Crawford, J. Satisfaction and Perceived Productivity when Professionals Work From Home. Res. Pract. Hum. Resour. Manag. 2007, 15, 37-62.

32. Hitt, L.M.; Tambe, P. Health care information technology, work organization, and nursing home performance. IlrRev. 2016, 69, 834-859. [CrossRef]

33. Wang, B.; Liu, Y.; Qian, J.; Parker, S.K. Achieving effective remote working during the COVID-19 pandemic: A work design perspective. Appl. Psychol. 2021, 70, 16-59. [CrossRef]

34. Toscano, F.; Zappalà, S. Social isolation and stress as predictors of productivity perception and remote work satisfaction during the COVID-19 pandemic: The role of concern about the virus in a moderated double mediation. Sustainability 2020, $12,9804$. [CrossRef]

35. Murphy, K.R.; Kroeker, L.P. Dimensions of Job Performance; Colorado State University Fort Collins: Fort Collins, CO, USA, 1988.

36. Randall, M.L.; Cropanzano, R.; Bormann, C.A.; Birjulin, A. Organizational politics and organizational support as predictors of work attitudes, job performance, and organizational citizenship behavior. J. Organ. Behav. Int. J. Ind. Occup. Organ. Psychol. Behav. 1999, 20, 159-174. [CrossRef]

37. De Menezes, L.M.; Kelliher, C. Flexible working, individual performance, and employee attitudes: Comparing formal and informal arrangements. Hum. Resour. Manag. 2017, 56, 1051-1070. [CrossRef]

38. Schaufeli, W.B.; Bakker, A.B. Defining and measuring work engagement: Bringing clarity to the concept. Work. Engagem. A Handb. Essent. Theory Res. 2010, 12, 10-24.

39. Kahn, W.A. Psychological conditions of personal engagement and disengagement at work. Acad. Manag. J. 1990, 33, 692-724. [CrossRef]

40. Maslach, C.; Schaufeli, W.B.; Leiter, M.P. Job burnout. Annu. Rev. Psychol. 2001, 52, 397-422. [CrossRef]

41. Schaufeli, W.B.; Salanova, M.; González-Romá, V.; Bakker, A.B. The measurement of engagement and burnout: A two sample confirmatory factor analytic approach. J. Happiness Stud. 2002, 3, 71-92. [CrossRef]

42. Bakker, A.B.; Demerouti, E. Towards a model of work engagement. Career Dev. Int. 2008, 13, 209-223. [CrossRef]

43. May, D.R.; Gilson, R.L.; Harter, L.M. The psychological conditions of meaningfulness, safety and availability and the engagement of the human spirit at work. J. Occup. Organ. Psychol. 2004, 77, 11-37. [CrossRef]

44. Schaufeli, W. Work engagement: What do we know and where do we go? Rom. J. Appl. Psychol. 2012, 14, 3-10.

45. Richman, A. Everyone wants an engaged workforce how can you create it? Workspan 2006, 49, 36-39.

46. Saks, A.M. Antecedents and consequences of employee engagement. J. Manag. Psychol. 2006, 21, 600-619. [CrossRef]

47. Simpson, M.R. Predictors of work engagement among medical-surgical registered nurses. West. J. Nurs. Res. 2009, 31, 44-65. [CrossRef] [PubMed]

48. Rich, B.L.; Lepine, J.A.; Crawford, E.R. Job engagement: Antecedents and effects on job performance. Acad. Manag. J. 2010, 53, 617-635. [CrossRef]

49. Bakker, A.B. An evidence-based model of work engagement. Curr. Dir. Psychol. Sci. 2011, 20, 265-269. [CrossRef]

50. Brunetto, Y.; Teo, S.T.; Shacklock, K.; Farr-Wharton, R. Emotional intelligence, job satisfaction, well-being and engagement: Explaining organisational commitment and turnover intentions in policing. Hum. Resour. Manag. J. 2012, 22, 428-441. [CrossRef]

51. Al Mehrzi, N.; Singh, S.K. Competing through employee engagement: A proposed framework. Int. J. Product. Perform. Manag. 2016, 65, 831-843. [CrossRef]

52. Albrecht, S.; Breidahl, E.; Marty, A. Organizational resources, organizational engagement climate, and employee engagement. Career Dev. Int. 2018, 23, 67-85. [CrossRef]

53. Agarwal, U.; Gupta, V. Relationships between job characteristics, work engagement, conscientiousness and managers' turnover intentions. Pers. Rev. 2018, 47, 353-377. [CrossRef]

54. vanMol, M.M.; Nijkamp, M.D.; Bakker, J.; Schaufeli, W.B.; Kompanje, E.J. Counterbalancing work-related stress? Work engagement among intensive care professionals. Aust. Crit. Care 2018, 31, 234-241. [CrossRef] [PubMed]

55. Zhong, L.; Wayne, S.J.; Liden, R.C. Job engagement, perceived organizational support, high-performance human resource practices, and cultural value orientations: A cross-level investigation. J. Organ. Behav. 2016, 37, 823-844. [CrossRef]

56. Knight, C.; Patterson, M.; Dawson, J. Work engagement interventions can be effective: A systematic review. Eur. J. Work. Organ. Psychol. 2019, 28, 348-372. [CrossRef]

57. Kahn, W.A. To be fully there: Psychological presence at work. Hum. Relat. 1992, 45, 321-349. [CrossRef]

58. Galanti, T.; Guidetti, G.; Mazzei, E.; Zappalà, S.; Toscano, F. Work from home during the COVID-19 outbreak: The impact on employees' remote work productivity, engagement, and stress. J. Occup. Environ. Med. 2021, 63, e426. [CrossRef] 
59. Demerouti, E.; Geurts, S. Towards a typology of work-home interaction. Community Work. Fam. 2004, 7, 285-309. [CrossRef]

60. Mostert, K. Work-home interaction as partial mediator between job resources and work engagement. S. Afr. Bus. Rev. 2006, 10, 53-74.

61. Bragard, I.; Hansez, I.; Coucke, P. Working conditions, job strain and work engagement among Belgian radiation oncologists. CancerRadiothérapie 2014, 18, 723-729. [CrossRef] [PubMed]

62. Rothmann, S.; Baumann, C. Employee engagement: The effects of work-home/home-work interaction and psychological conditions. S. Afr. J. Econ. Manag. Sci. 2014, 17, 515-530. [CrossRef]

63. Verweij, H.; van Hooff, M.L.; van der Heijden, F.M.; Prins, J.T.; Lagro-Janssen, A.L.; van Ravesteijn, H.; Speckens, A.E. The relationship between work and home characteristics and work engagement in medical residents. Perspect. Med Educ. 2017, 6, 227-236. [CrossRef] [PubMed]

64. Listau, K.; Christensen, M.; Innstrand, S.T. Work Engagement: A Double-Edged Sword? A Study of the Relationship between Work Engagement and the Work-Home Interaction Using the ARK Research Platform. Scand. J. Work. Organ. Psychol. 2017, 2, 1-13. [CrossRef]

65. Vayre, E.; Vonthron, A.M. Identifying work-related internet's uses-At work and outside usual workplaces and hours-And their relationships with work-home interface, work engagement, and problematic internet behavior. Front. Psychol. 2019, 10, 2118. [CrossRef]

66. Ispas, S.A.; Iliescu, D. Work-life interaction as a mediator between work factors and outcomes. Psihol. Resur. Um. 2017, 15, 106-124.

67. Romeo Delgado, M.; YepesiBaldó, M.; Soria Verde, M.Á.; Jayme Zaro, M. Impact of the COVID-19 Pandemic on Higher Education: Characterizing the Psychosocial Context of the Positive and Negative Affective States Using Classification and Regression Trees. Front. Psychol. 2021, 2021, 714397. [CrossRef]

68. Mostert, K.; Peeters, M.; Rost, I. Work-home interference and the relationship with job characteristics and well-being: A South African study among employees in the construction industry. Stress Health 2011, 27, e238-e251. [CrossRef]

69. Vischer, J.C. The effects of the physical environment on job performance: Towards a theoretical model of workspace stress. Stress and health. J. Int. Soc. Investig. Stress 2007, 23, 175-184. [CrossRef]

70. Demerouti, E.; Geurts, S.A.E.; Kompier, M. Positive and negative work-home interaction: Prevalence and correlates. Equal. Oppor. Int. 2004, 23, 6-35. [CrossRef]

71. Demerouti, E.; Taris, T.W.; Bakker, A.B. Need for recovery, home-work interference and performance: Is lack of concentration the link? J. Vocat. Behav. 2007, 71, 204-220. [CrossRef]

72. Volman, F.E.; Bakker, A.B.; Xanthopoulou, D. Recovery at home and performance at work: A diary study on self-family facilitation. Eur. J. Work. Organ. Psychol. 2013, 22, 218-234. [CrossRef]

73. Menges, J.I.; Tussing, D.V.; Wihler, A.; Grant, A.M. When job performance is all relative: How family motivation energizes effort and compensates for intrinsic motivation. Acad. Manag. J. 2017, 60, 695-719. [CrossRef]

74. Keene, J.R.; Reynolds, J.R. The job costs of family demands: Gender differences in negative family-to-work spillover. J. Fam. Issues 2005, 26, 275-299. [CrossRef]

75. Demerouti, E.; Bakker, A.B.; Voydanoff, P. Does home life interfere with or facilitate job performance? Eur. J. Work. Organ. Psychol. 2010, 19, 128-149. [CrossRef]

76. Nart, S.; Batur, O. The relation between work-family conflict, job stress, organizational commitment and job performance: A study on Turkish primary teachers. Eur. J. Res. Educ. 2014, 2, 72-81. [CrossRef]

77. Ajala, E.M. Work-family-conflict and family-work-conflict as correlates of job performance among working mothers: Implications for industrial social workers. Afr. J. Soc. Work. 2017, 7, 52-62.

78. Patel, C.J.; Govender, V.; Paruk, Z.; Ramgoon, S. Working mothers: Family-work conflict, job performance and family/work variables. SA J. Ind. Psychol. 2006, 32, 39-45. [CrossRef]

79. Berkowsky, R.W. When you just cannot get away: Exploring the use of information and communication technologies in facilitating negative work/home spillover. Inf. Commun. Soc. 2013, 16, 519-541. [CrossRef]

80. Dahlberg, L. Loneliness during the COVID-19 pandemic. Aging Ment. Health 2021, 25, 1161-1164. [CrossRef] [PubMed]

81. Kato, T.A.; Sartorius, N.; Shinfuku, N. Forced social isolation due to COVID-19 and consequent mental health problems: Lessons from hikikomori. Psychiatry Clin. Neurosci. 2020, 74, 496-512. [CrossRef]

82. de Jong Gierveld, J. A review of loneliness: Concept and definitions, determinants and consequences. Rev. Clin. Gerontol. 1998, 8 73-80. [CrossRef]

83. Spithoven, A.W.M.; Cacioppo, S.; Goossens, L.; Cacioppo, J.T. Genetic contributions to loneliness and their relevance to the evolutionary theory of loneliness. Perspect. Psychol. Sci. 2019, 14, 376-396. [CrossRef] [PubMed]

84. Çolak, M.; Çetin, C. Loneliness and Cyberloafing in the Time of COVID-19: A Psychological Perspective. Int. J. Contemp. Manag. 2021, 57, 15-27. [CrossRef]

85. Ay, F.A. The relationships between abusive management, workplace loneliness and organizational cynicism: A study for health professionals. J. Int. Soc. Res. 2015, 41, 1116-1126.

86. Zhou, X. A Review of Researches Workplace Loneliness. Psychology 2018, 9, 1005-1022. [CrossRef]

87. Lowman, G.H. What about the lonely? Bridging loneliness, pandemics, and IO psychology. Ind. Organ. Psychol. 2021, 14, 130-132. [CrossRef] 
88. Lam, L.W.; Lau, D.C. Feeling lonely at work: Investigating the consequences of unsatisfactory workplace relationships. Int. J. Hum. Resour. Manag. 2012, 23, 4265-4282. [CrossRef]

89. Ozcelik, H.; Barsade, S.G. No Employee an Island: Workplace Loneliness and Job Performance. Acad. Manag. J. 2018, 61, 2343-2366. [CrossRef]

90. Deniz, S. Effect of Loneliness in the Workplace on Employees' Job Performance: A Study for Hospital Employees. Int. J. Health Serv. Res. Policy 2019, 4, 214-224. [CrossRef]

91. Firoz, M.; Chaudhary, R. The impact of workplace loneliness on employee outcomes: What role does psychological capital play? Pers. Rev. 2021. [CrossRef]

92. Firoz, M.; Chaudhary, R.; Khan, A. Desolated milieu: Exploring the trajectory of workplace loneliness (2006-2019). Manag. Res. Rev. 2020, 44, 757-780. [CrossRef]

93. Basit, A.A.; Azeem, M.U.; Haq, I. Towards making inclusive organizations: A conditional process analysis of workplace loneliness In Academy of Management Proceedings. Acad. Manag. 2019, 2019, 16463.

94. Jung, H.S.; Song, M.K.; Yoon, H.H. The Effects of Workplace Loneliness on Work Engagement and Organizational Commitment: Moderating Roles of Leader-Member Exchange and Coworker Exchange. Sustainability 2021, 13, 948. [CrossRef]

95. Tian, G.; Pu, L.; Ren, H. Gender differences in the effect of workplace loneliness on organizational citizenship behaviors mediated by work engagement. Psychol. Res. Behav. Manag. 2021, 14, 1389-1398. [CrossRef] [PubMed]

96. Larson, B.Z.; Vroman, S.R.; Makarius, E.E. A guide to managing your (newly) remote workers. Harv. Bus. Rev. 2020, 18, 1-6.

97. Eisenberger, R.; Huntington, R.; Hutchison, S.; Sowa, D. Perceived organizational support. J. Appl. Psychol. 1986, 71, 500-507. [CrossRef]

98. Schwarzer, R.; Knoll, N.; Rieckmann, N. Social support. Health Psychol. 2004, 158, $283-292$.

99. Brouwers, A.; Evers, W.J.; Tomic, W. Self-efficacy in eliciting social support and burnout among secondary-school teachers. J. Appl. Soc. Psychol. 2001, 31, 1474-1491. [CrossRef]

100. Baruch-Feldman, C.; Brondolo, E.; Ben-Dayan, D.; Schwartz, J. Sources of social support and burnout, job satisfaction, and productivity. J. Occup. Health Psychol. 2002, 7, 84-93. [CrossRef]

101. Beehr, T.A.; Jex, S.M.; Stacy, B.A.; Murray, M.A. Work stressors and coworker support as predictors of individual strain and job performance. J. Organ. Behav. 2000, 21, 391-405. [CrossRef]

102. AbuAlRub, R.F. Job stress, job performance, and social support among hospital nurses. J. Nurs. Scholarsh. 2004, 36, 73-78. [CrossRef]

103. Amarneh, B.H.; Abu Al-Rub, R.F.; Abu Al-Rub, N.F. Co-workers' support and job performance among nurses in Jordanian hospitals. J. Res. Nurs. 2010, 15, 391-401. [CrossRef]

104. Branscum, P.; Haider, T.; Brown, D.; Sharma, M. Using emotional intelligence and social support to predict job performance of health educators. Am. J. Health Educ. 2016, 47, 309-314. [CrossRef]

105. Ling, S.M.; Bhatti, M.A. Work stress and job performance in Malaysia academic sector: Role of social support as moderator. J. Econ. Manag. Trade 2014, 4, 1986-1998. [CrossRef]

106. Nasurdin, A.M.; Ling, T.C.; Khan, S.N. Linking social support, work engagement and job performance in nursing. Int. J. Bus. Soc. 2018, 19, 363-386.

107. Schaufeli, W.B.; Salanova, M. Work engagement: An emerging psychological concept and its implications for organizations. In Research in Social Issues in Management: Managing Social and Ethical Issues in Organizations; Gilliland, S.W., Steiner, D.D., Skarlicki, D.P., Eds.; Information Age Publishers: Greenwich, UK, 2007; Volume 5.

108. Xanthopoulou, D.; Bakker, A.B.; Heuven, E.; Demerouti, E.; Schaufeli, W.B. Working in the sky: A diary study on work engagement among flight attendants. J. Occup. Health Psychol. 2008, 13, 345-356. [CrossRef]

109. Xanthopoulou, D.; Bakker, A.B.; Demerouti, E.; Schaufeli, W.B. Work engagement and financial returns: A diary study on the role of job and personal resources. J. Occup. Organ. Psychol. 2009, 82, 183-200. [CrossRef]

110. Halbesleben, J.R. A meta-analysis of work engagement: Relationships with burnout, demands, resources, and consequences Work. Engagem. A Handb. Essent. Theory Res. 2010, 8, 102-117.

111. Rožman, M.; Štrukelj, T. Organisational climate components and their impact on work engagement of employees in medium-sized organisations. Econ. Res.-Ekon. Istraživanja 2021, 34, 775-806. [CrossRef]

112. Ross, R.R.; Altmaier, E.M.; Russell, D.W. Job stress, social support, and burnout among counseling center staff. J. Couns. Psychol. 1989, 36, 464. [CrossRef]

113. Leiter, M.P.; Bakker, A.B. Work engagement: Introduction. In Work Engagement: A Handbook of Essential Theory and Research; Psychology Press: New York, NY, USA, 2010; pp. 1-9.

114. Woodhead, E.L.; Northrop, L.; Edelstein, B. Stress, social support, and burnout among long-term care nursing staff. J. Appl. Gerontol. 2016, 35, 84-105. [CrossRef]

115. Sawang, S. Is there an inverted U-shaped relationship between job demands and work engagement: The moderating role of social support? Int. J. Manpow. 2012, 33, 178-186. [CrossRef]

116. Glaser, D.N.; Tatum, B.C.; Nebeker, D.M.; Sorenson, R.C.; Aiello, J.R. Workload and social support: Effects on performance and stress. Hum. Perform. 1999, 12, 155-176. [CrossRef]

117. Sargent, L.D.; Terry, D.J. The moderating role of social support in Karasek's job strain model. Work. Stress 2000, 14, $245-261$. [CrossRef] 
118. Siu, O.L.; Lu, C.Q.; Spector, P.E. Direct and indirect relationship between social stressors and job performance in Greater China: The role of strain and social support. Eur. J. Work. Organ. Psychol. 2013, 22, 520-531. [CrossRef]

119. Foy, T.; Dwyer, R.J.; Nafarrete, R.; Hammoud, M.S.S.; Rockett, P. Managing job performance, social support and work-life conflict to reduce workplace stress. Int. J. Product. Perform. Manag. 2019, 68, 1018-1041. [CrossRef]

120. Schreurs, B.H.; Hetty van Emmerik, I.J.; Guenter, H.; Germeys, F. A weekly diary study on the buffering role of social support in the relationship between job insecurity and employee performance. Hum. Resour. Manag. 2012, 51, 259-279. [CrossRef]

121. Wang, M.L.; Tsai, L.J. Work-family conflict and job performance in nurses: The moderating effects of social support. J. Nurs. Res. 2014, 22, 200-207. [CrossRef] [PubMed]

122. Bentley, T.A.; Teo, S.T.T.; McLeod, L.; Tan, F.; Bosua, R.; Gloet, M. The role of organisational support in teleworker wellbeing: A socio-technical systems approach. Appl. Ergon. 2016, 52, 207-215. [CrossRef]

123. Eisapareh, K.; Nazari, M.; Kaveh, M.H.; Ghahremani, L. The relationship between job stress and health literacy with the quality of work life among Iranian industrial workers: The moderating role of social support. Curr. Psychol. 2020, 14, 1-9. [CrossRef]

124. Tu, Y.; Li, D.; Wang, H.J. COVID-19-induced layoff, survivors' COVID-19-related stress and performance in hospitality industry: The moderating role of social support. Int. J. Hosp. Manag. 2021, 95, 102912. [CrossRef]

125. Zhou, M.; Lin, W. Adaptability and life satisfaction: The moderating role of social support. Front. Psychol. 2016, 7, 1134. [CrossRef]

126. Yang, F.; Wen, D. Combating workplace loneliness climate and enhancing team performance: The roles of leader humor and team bureaucratic practices. J. Bus. Res. 2021, 136, 305-315. [CrossRef]

127. Guidetti, G.; Converso, D.; Loera, B.; Viotti, S. Concerns about change and employee wellbeing: The moderating role of social support. J. Workplace Learn. 2018, 30, 216-228. [CrossRef]

128. Taylor, S.E. Social support: A review. In The Oxford Handbook of Health Psychology; Friedman, H.S., Ed.; Oxford University Press: Oxford, UK, 2011; pp. 189-214.

129. Klassen, R.D.; Jacobs, J. Experimental comparison of web, electronic and mail survey technologies in operations management. J. Oper. Manag. 2001, 19, 713-728. [CrossRef]

130. Podsakoff, P.M.; MacKenzie, S.B.; Lee, J.-Y.; Podsakoff, N.P. Common method biases in behaviouralresearch: A critical review of the literature and recommended remedies. J. Appl. Psychol. 2003, 88, 879-903. [CrossRef]

131. Amankwaa, A.; Gyensare, M.A.; Susomrith, P. Transformational leadership with innovative behaviour: Examining multiple mediating paths with PLS-SEM. Leadersh. Organ. Dev. J. 2019, 40, 402-420. [CrossRef]

132. Schaufeli, W.B.; Bakker, A.B.; Salanova, M. The measurement of work engagement with a short questionnaire: A cross-national study. Educ. Psychol. Meas. 2006, 66, 701-716. [CrossRef]

133. Petrović, I.B.; Vukelić, M.; Čizmić, S. Work engagement in Serbia: Psychometric properties of the Serbian version of the Utrecht Work Engagement Scale (UWES). Front. Psychol. 2017, 8, 1799. [CrossRef]

134. Williams, L.J.; Anderson, S.E. Job satisfaction and organizational commitment as predictors of organizational citizenship and in-role behaviors. J. Manag. 1991, 17, 601-617. [CrossRef]

135. Geurts, S.A.; Taris, T.W.; Kompier, M.A.; Dikkers, J.S.; Van Hooff, M.L.; Kinnunen, U.M. Work-home interaction from a work psychological perspective: Development and validation of a new questionnaire, the SWING. Work. Stress 2005, 19, 319-339. [CrossRef]

136. Russell, D.; Peplau, L.A.; Ferguson, M.L. Developing a measure of loneliness. J. Personal. Assess. 1978, 42, 290-294. [CrossRef]

137. Morgeson, F.P.; Humphrey, S.E. The Work Design Questionnaire (WDQ): Developing and validating a comprehensive measure for assessing job design and the nature of work. J. Appl. Psychol. 2006, 91, 13-21. [CrossRef]

138. Hair, J.F., Jr.; Sarstedt, M.; Hopkins, L.; Kuppelwieser, V.G. Partial least squares structural equation modeling (PLS-SEM): An emerging tool in business research. Eur. Bus. Rev. 2014, 26, 106-121. [CrossRef]

139. Hair, J.F.; Sarstedt, M.; Pieper, T.M.; Ringle, C.M. The use of partial least squares structural equation modeling in strategic management research: A review of past practices and recommendations for future applications. Long Range Plan. 2012, 45, 320-340. [CrossRef]

140. Ringle, C.M.; Sarstedt, M.; Mitchell, R.; Gudergan, S.P. Partial least squares structural equation modeling in HRM research. Int. J. Hum. Resour. Manag. 2020, 31, 1617-1643. [CrossRef]

141. Anderson, J.C.; Gerbing, D.W. Structural equation modeling in practice: A review and recommended two-step approach. Psychol. Bull. 1988, 103, 411-423. [CrossRef]

142. Nunnally, J.C.; Bernstein, I.H. Psychometric Theory; McGrawHill: New York, NY, USA, 1994.

143. Hair, J.; Hollingsworth, C.L.; Randolph, A.B.; Chong, A.Y.L. An updated and expanded assessment of PLS-SEM in information systems research. Ind. Manag. Data Syst. 2017, 111, 442-458. [CrossRef]

144. Fornell, C.; Larcker, D.F. Evaluating structural equation models with unobservable variables and measurement error. J. Mark. Res. 1981, 18, 39-50. [CrossRef]

145. Chin, W.W. How to write up and report PLS analysis. In Handbook of Partial Least Squares; Vinzi, V.E., Chin, W.W., Henseler, J., Wang, H., Eds.; Springer: Heidelberg, Germany, 2010; pp. 655-690.

146. Henseler, J.; Ringle, C.M.; Sarstedt, M. A new criterion for assessing discriminant validity in variance-based structural equation modeling. J. Acad. Mark. Sci. 2015, 43, 115-135. [CrossRef]

147. Stone, M. Cross-Validatory Choice and Assessment of Statistical Predictions. J. R. Stat. Soc. 1974, 36, 111-147. [CrossRef]

148. Geisser, S. A Predictive Approach to the Random Effects Model. Biometrika 1974, 61, 101-107. [CrossRef] 
149. Henseler, J.; Dijkstra, T.K.; Sarstedt, M.; Ringle, C.M.; Diamantopoulos, A.; Straub, D.W.; Ketchen, D.J.; Hair, J.F.; Hult, G.T.M.; Calantone, R.J. Common Beliefs and Reality about Partial Least Squares: Comments on Rönkkö\&Evermann (2013). Organ. Res. Methods 2014, 17, 182-209. [CrossRef]

150. Hu, L.-T.; Bentler, P.M. Fit Indices in Covariance Structure Modeling: Sensitivity to Underparameterized Model Misspecification. Psychol. Methods 1998, 3, 424-453. [CrossRef]

151. Zhao, X.; Lynch, J.G., Jr.; Chen, Q. Reconsidering Baron and Kenny: Myths and truths about mediation analysis. J. Consum. Res. 2010, 37, 197-206. [CrossRef]

152. Nitzl, C.; Roldan, J.L.; Cepeda, G. Mediation analysis in partial least squares path modeling: Helping researchers discuss more sophisticated models. Ind. Manag. Data Syst. 2016, 116, 1849-1864. [CrossRef]

153. Connor, M.O.; Conboy, K.; Dennehy, D. COVID-19 affected remote workers: A temporal analysis of information system development during the pandemic. J. Decis. Syst. 2021, 1-27. [CrossRef]

154. Mohezar, S.; Jaafar, N.I.; Akbar, W. Remote Working: New Spaces and New Work Design. In Achieving Quality of Life at Work; Springer: Singapore, 2021; pp. 51-67. [CrossRef]

155. Nurse, J.R.C.; Williams, N.; Collins, E.; Panteli, N.; Blythe, J.; Koppelman, B. Remote Working Pre- and Post-COVID-19: An Analysis of New Threats and Risks to Security and Privacy, HCI International 2021-Posters. In Proceedings of the HCII 2021 Communications in Computer and Information Science, Virtual Event, 24-29 July 2021. [CrossRef]

156. Gomes, C.C. Remote Work: The Need of Human Factorsand Ergonomics to Improve Human Health and Wellbeing, Advances in Ergonomics in Design. In AHFE 2021 Lecture Notes in Networks and Systems 2021; Rebelo, F., Ed.; Springer Nature: Cham, Switzerland, 2021. [CrossRef]

157. İlhan, Ü.D. A Rapid Implementation of Remote Work as a Strategy in Response to COVID-19: An Examination in Terms of Work-Life Balance, Management Strategies to Survive in a Competitive Environment. Contributions to Management Science; Dincer, H., Yüksel, S., Eds.; Springer Nature: Cham, Switzerland, 2021. [CrossRef]

158. Konstantinov, V.; Berdenova, S.; Satkangulova, G.; Reznik, A.; Isralowitz, R. COVID-19 impact on Kazakhstan university student fear, mental health, and substance use. Int. J. Ment. Health Addict. 2020, 18, 1-7. [CrossRef] [PubMed] 